\title{
Prosthodontic Rehabilitation of Edentulous Patient with Implant Supported Hybrid Prosthesis: A Case Report
}

\author{
Aquib Javaid Mughal ${ }^{1}$ Ritu Batra ${ }^{1} \quad$ Manjit Kumar ${ }^{1} \quad$ Ajay Bansal ${ }^{1}$ Himani Jain ${ }^{1}$ \\ ${ }^{1}$ Department of Prosthodontics, Bhojia Dental College and Hospital, \\ Baddi, Solan, Himachal Pradesh, India \\ Address for correspondence Aquib Javaid Mughal, Department of \\ Prosthodontics, Bhojia Dental College and Hospital, Baddi, Solan \\ 173205, Himachal Pradesh, India (e-mail: aquib.mughal@gmail.com).
}

Dent J Adv Stud 2018;6:122-125

\begin{abstract}
Keywords

- framework hybrid prosthesis

- implant

- screw retained prosthesis

A hybrid denture is fabricated over a metal framework that is retained by screws into the implants. The anterior part of a hybrid denture is fixed on implants and the posterior part of the denture is cantilevered. This case report presents the fabrication of a maxillary implant retained hybrid prosthesis. Four implants were placed in the maxillary arch. Framework was waxed, castable abutments were used, after-casting denture teeth were waxed to the hybrid framework, and a final try-in was done to verify and correct maxillomandibular relations before processing. The prosthesis was inserted after verifying fit of the framework.
\end{abstract}

\section{Introduction}

The prosthodontics rehabilitation of completely edentulous patient is a challenging task. The tissue changes under complete denture prosthesis, anatomic limitations and the psychological make-up of the patient sometimes leads to complications. ${ }^{1}$

Elderly patients are worried about not only functional mastication but also, due to increase in life expectancy, esthetics that are lost due to the loss of the teeth. Treatment modalities may vary from removable to fixed prostheses. ${ }^{2}$ Treatment choice may vary due to anatomical limitations and personal preference of the patient, including surgical intervention to restore the soft tissue and bone. ${ }^{3}$ Hybrid prosthesis and implant-supported overdentures provide support to the soft tissues as compared with the traditional fixed prosthesis.

Because of combined vertical and horizontal bone loss especially in the maxilla and because adequate number of implants cannot be placed, the traditional fixed prosthesis is not possible. Maintenance of oral hygiene, esthetics, phonetics, and comfort is difficult with traditional fixed prosthesis. These complications can be overcome with hybrid prosthesis that can easily replace the soft tissues and can also resolve problems of component fracture, screw loosening, and bone resorption. ${ }^{4}$ received

November 8, 2018 accepted after revision

November 16, 2018

published online

January 22, 2019
Zarb and Symington developed the hybrid prosthesis by attaching denture teeth with heat-polymerized acrylic resin to a cast metal substructure. ${ }^{5}$ The anterior part of a maxillary hybrid denture is fixed on implants whereas the posterior part of the denture is extended and cantilevered from implants. Prosthetic rehabilitation in edentulous patients can be performed by using screw-retained hybrid prosthesis, screw-retained metal ceramic prosthesis, and cement-retained metal ceramic prosthesis. Use of screw-retained prosthesis is recommended for patients suffering from weak denture retention because this type of prosthesis can be easily placed and retrieved. ${ }^{6}$ Apart from the aforementioned advantages, hybrid prostheses can also replace soft tissue defects. However, lack of passive fit in the framework and distortion are major obstacles in the process of prosthesis fabrication. ${ }^{7}$ Also in screwretained prostheses, sometimes the screw access channel has to be placed in buccal, lingual, or occlusal aspect of the prosthesis due to the position of the implant, which may interfere with the esthetics and morphology of occlusal surface. ${ }^{8}$ Generally, hybrid prosthesis is the recommended treatment for patients suffering from severe alveolar ridge resorption. ${ }^{9}$

This clinical report presents the fabrication of screwretained maxillary implant-supported hybrid prosthesis.
C2018 by Bhojia Dental College and Hospital affiliated to Himachal Pradesh University

\section{License terms}

$10.1055 / \mathrm{s}-0038-1677630$

ISSN 2321-1482. 


\section{Case}

A 56-year-old male patient reported to the Department of Prosthodontics, Bhojia Dental College and Hospital, Baddi, Himachal Pradesh, with history of missing all maxillary teeth. On intraoral examination, the patient revealed partially dentulous mandibular arch and completely edentulous maxillary arch. The etiology of loss of the teeth was due to periodontal disease. The patient was in possession of removable prosthesis for the maxilla and mandible but was not satisfied and wanted fixed prostheses. Treatment planning was done, and treatment option for hybrid prosthesis was discussed with the patient.

\section{Surgical Phase}

Four internal hexed two-stage titanium implants (ADIN, Afula, Israel) were inserted according to manufacturer's recommendations. Implant locations were 13, 15, 22, and 24. Implants were slightly submerged ( - Fig. 1 ). After 4 months of postsurgical period, gingival formers were placed with second-stage surgery.

\section{Prosthetic Phase}

After 2 weeks, gingival formers were removed, impression copings were connected, and impressions were made using open-tray technique. Long fixation screws with impression copings were used for better connection allowing precise connection to the implant. Windows were cut in the tray to allow internal screw to be loosened. Tray adhesive was applied to the tray before making the impression. C-Silcone (Zetaplus, Zhermack SpA, Italy) material was used. Impression copings were incorporated into the impression, and retained screws were unscrewed and removed. Then tray was removed capturing the impression copings ( - Fig. 2 ). Gingival formers were again attached to the implants in the patient's mouth.

Impressions were poured in die stone (Ultrarock, Kalabhai Karson Ltd., Mumbai, India) to form master casts. Record bases and occlusal rims were fabricated, and maxillomandibular

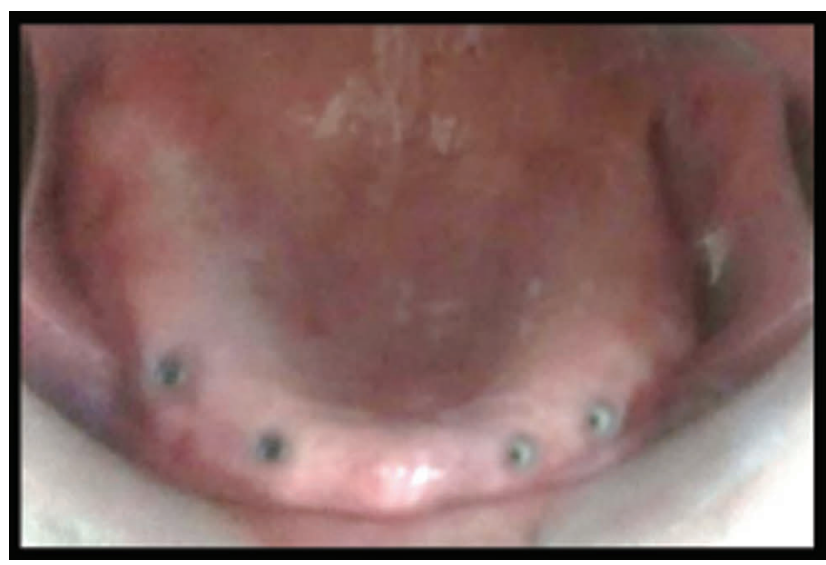

Fig. 1 Implants in place.

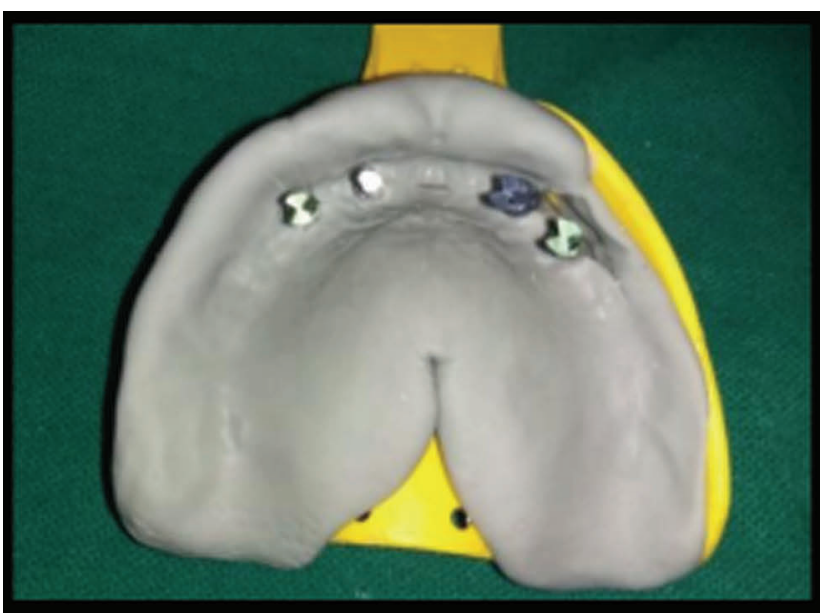

Fig. 2 Impression with implant analogs in place.

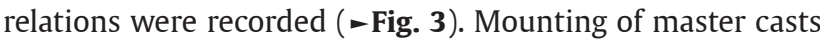
was done, and castable abutments were attached to the implant analogs in the master cast and connected together with the pattern resin to form a jig (-Fig. 4).

This jig was then tried in the patient's mouth. The framework was waxed, cast, recovered, and fitted on the master cast, and then was tried in the patient's mouth ( $\mathbf{- F i g . ~ 5 )}$. Teeth were waxed and tried to verify the jaw relations.

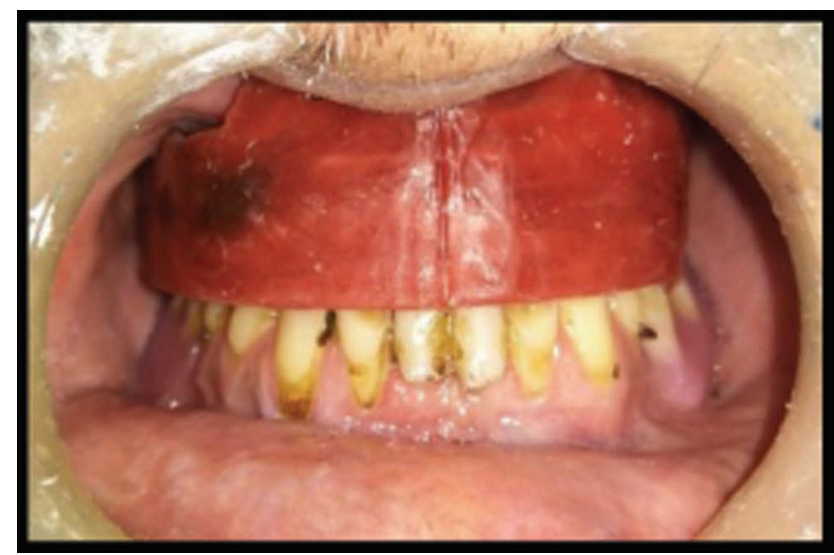

Fig. 3 Jaw relations.

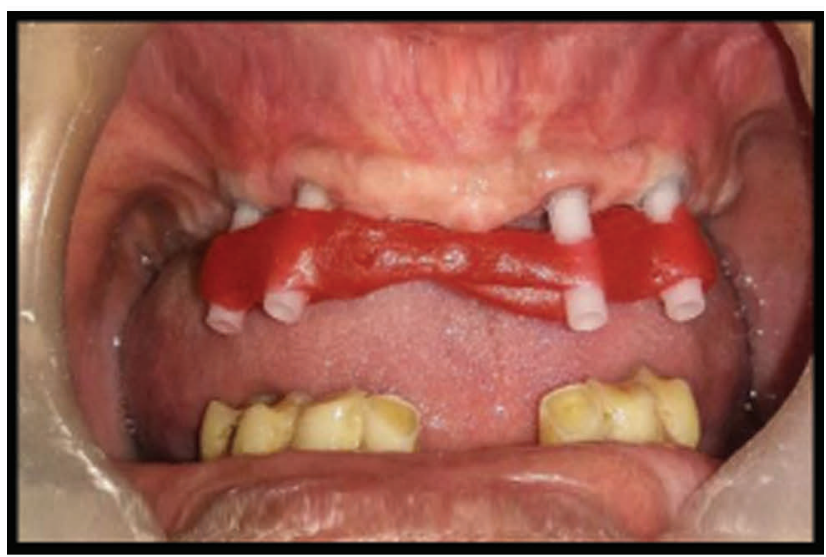

Fig. 4 Jig try-in in patient's mouth. 


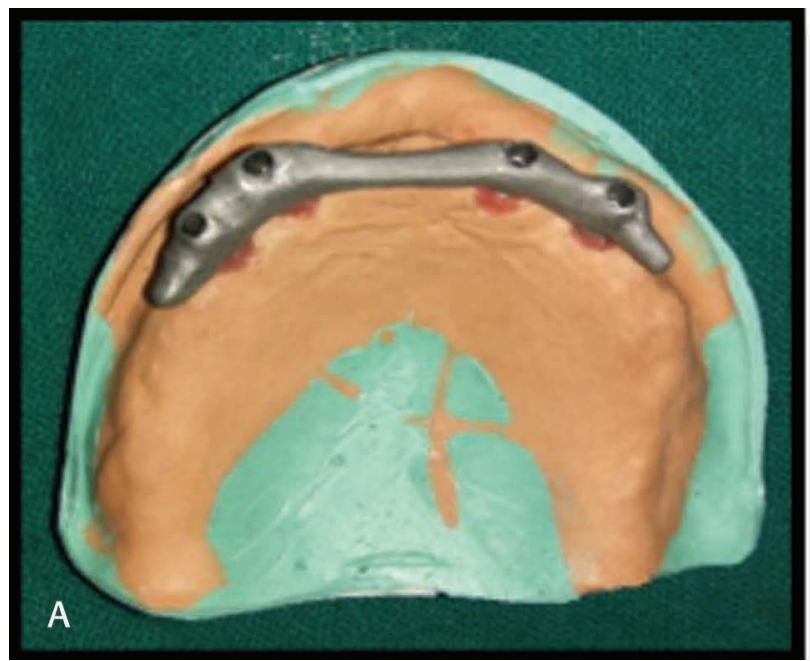

Fig. 5 (A, B) Framework in patient's mouth.

Processing of the hybrid prosthesis was done conventionally. The prosthesis was finished polished and screwed

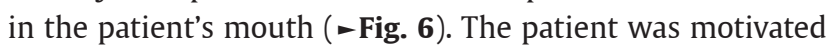
and educated for oral hygiene, recall, and maintenance of the prosthesis.
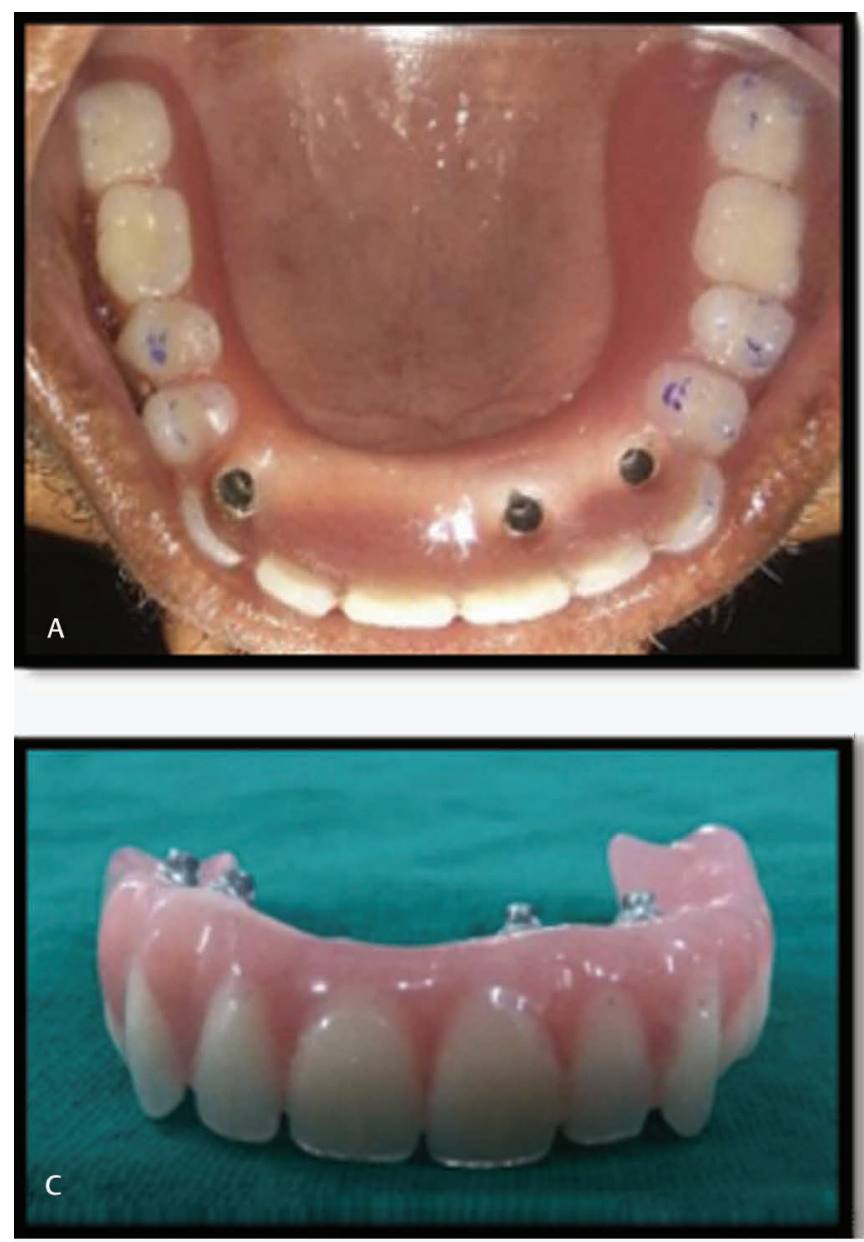

Fig. 6 (A-D) Hybrid prosthesis in situ.

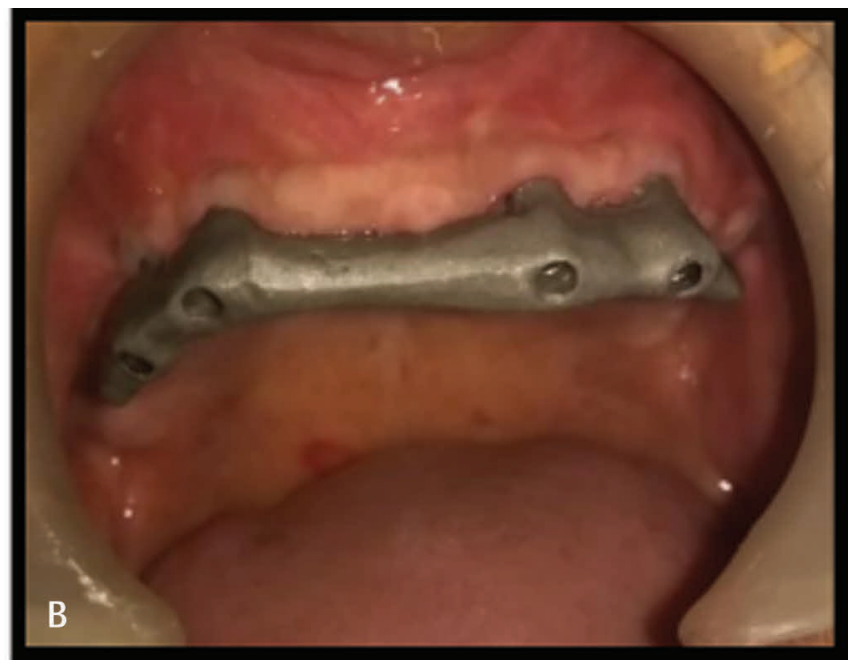

\section{Discussion}

If interocclusal space is sufficient, better esthetics can be achieved. Bulkiness of metal substructure and replacement of soft tissues are difficult with conventional fixed
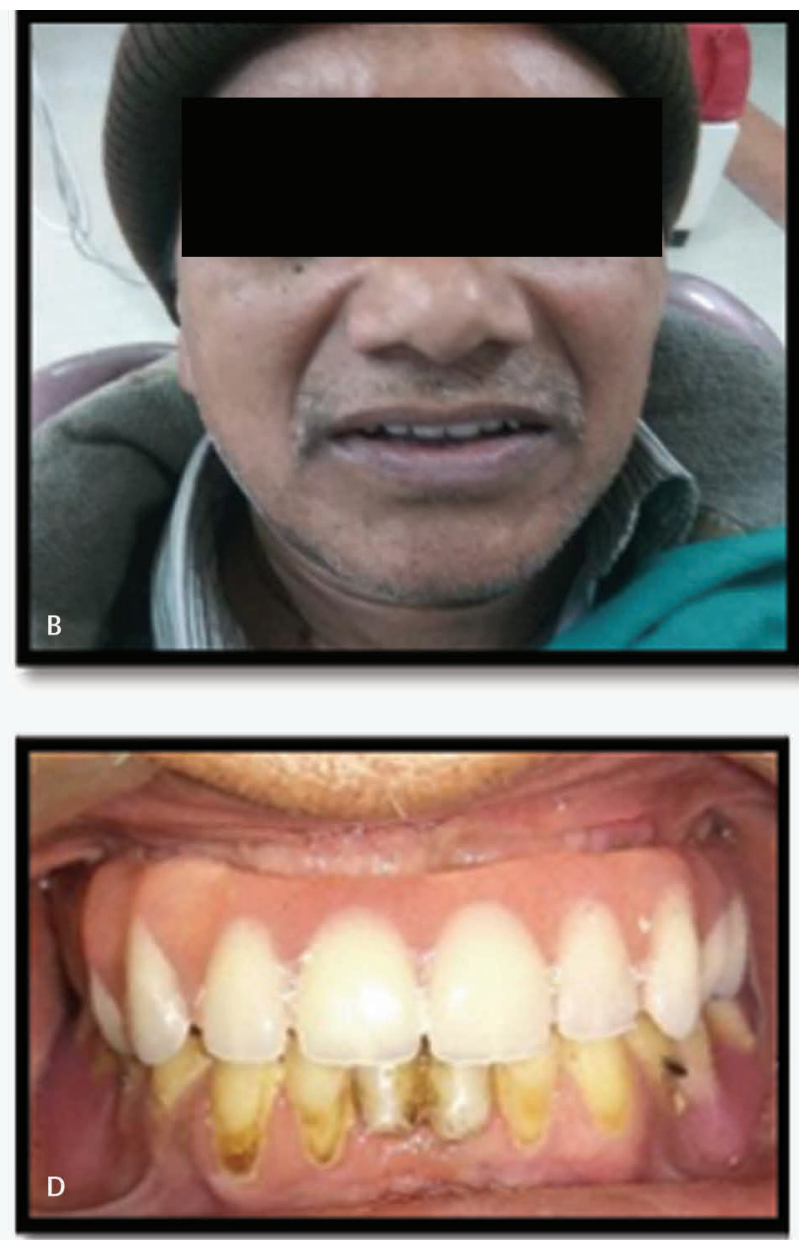
prosthesis. In addition to better esthetics, hybrid prosthesis works as shock absorber and better stress distribution to implants. On the other hand, prosthetic part of hybrid prosthesis replaces the soft tissues and offer better oral hygiene maintenance.

In excessive parafunctional habits, polymethylmethacrylate fails to provide mechanical, biological, and esthetic properties. To reduce the chances of fracture, the hybrid denture gets the support from the metal framework. The most important technical aspect of retained prostheses is the passive fit of the substructure. There are numerous methods to achieve passive fit, but still flaws exist in impression making techniques and casting procedures, which leads to errors. We require internal surface adjustments of the suprastructure and precise laboratory work. If the framework is not having an adequate fit, it should be cut, joined with acrylic resin and soldered, which might add to the costs to both the patient and the dentist.

Rehabilitation of the completely edentulous patient with hybrid denture leads to better function and esthetics than conventional overdentures.

\section{Conclusion}

This technique describes the screw-retained system for hybrid prosthesis and is indicated for complete dental reconstruction, especially in patients with severe bone loss. Implants can be easily accessed through unscrewing the metal framework.

\section{Conflict of Interest}

None declared.

\section{References}

1 Karthigeyan S, Ali SA, Mohan K, Deivanai M. An organized start to implant-supported prosthesis. Contemp Clin Dent 2013;4(1):90-93

2 Montero J, Macedo de Paula C, Albaladejo A. The "Toronto prosthesis," an appealing method for restoring patients candidates for hybrid overdentures: a case report. J Clin Exp Dent 2012;4(5):e309-e312

3 Steigmann M. Aesthetic flap design for correction of buccal fenestration defects. Pract Proced Aesthet Dent 2008; 20(8):487-493, quiz 494

4 Kwon T, Bain PA, Levin L. Systematic review of short(5-10 years) and long-term (10 years or more) survival and success of full-arch fixed dental hybrid prostheses and supporting implants. J Dent 2014;42(10):1228-1241

5 Cobb GW Jr, Metcalf AM, Parsell D, Reeves GW. An alternate treatment method for a fixed-detachable hybrid prosthesis: a clinical report. J Prosthet Dent 2003;89(3):239-243

6 Salenbauch NM, Langner J. New ways of designing suprastructures for fixed implant-supported prostheses. Int J Periodontics Restorative Dent 1998;18(6):604-612

7 Balshi TJ. Preventing and resolving complications with osseointegrated implants. Dent Clin North Am 1989;33(4):821-868

8 Golden WG, Wee AG, Danos TL, Cheng AC. Fabrication of a two-piece superstructure for a fixed detachable implantsupported mandibular complete denture. J Prosthet Dent 2000;84(2):205-209

9 Taylor TD, Agar JR. Twenty years of progress in implant prosthodontics. J Prosthet Dent 2002;88(1):89-95 